\title{
SEMI-ENCLOSED SEAS AS A COMPLEX HYDROLOGICAL SYSTEM
}

\section{THE NOTION OF THE SEMI-ENCLOSED SEA}

Seas, being part of the ocean, are usually divided into coastal seas (open) and inland seas (enclosed). Recently, there appeared in scientific literature the notion of the so-called semi-enclosed sea; it has been distinguished not so much as a result of its morphonometrical characteristics but rather due to its specific hydrological character. The semi-enclosed sea can be both an inland sea (mediterranean) with limited contact with the open sea or with the ocean and a coastal sea (fringing) having direct contact with the ocean.

Semi-enclosed seas are peculiar hydrographic entities that usually occur on the border of fresh and salt waters; their salinity being usually small (at least in the moderate climatic zone); that is why they are called brackish waters. The hydrological environment of those seas is usually determined by two hydrological factors: inland (fresh) water inflow and ocean (salt) inflow. The former is of continuous character with varying intensity throughout the year and usually small amplitude (when analyzing river inflow globally). The latter factor occurs sporadically, under favourable weather conditions; it is often quite violent, supplies great amounts of water, thus affecting the sea level.

The hydrological environment of semi-enclosed seas is characterized by quite changeable mutual relations between those factors; therefore such seas differ considerably from each other. Also in one and the same sea the relations of the two factors vary - both in time and in various parts of the semi-enclosed sea. In seas with varied coastline, various parts are usually characterized by diversity of the marine environment. This particularly refers to the salinity of the water. The regions situated in the vicinity of straits connecting the semi-enclosed sea with the ocean have the salinity similar to that of the ocean, while those lying close to the river mouths are considerably desalted. Ocean inflows supply waters of higher density which subsequently remain in the sea depths; they cause 
higher salinity and its clear-cut vertical gradient considerably affecting chemical and biological processes.

Thus we distinguish two types of semi-enclosed seas: those with positive balance and seas with negative balance. In the former, river inflow and precipitation highly exceed evaporation from the sea surface; as a result, the excessive water flows into the ocean (open sea). In the latter case, evaporation exceeds river inflow and precipitation, and water losses are later supplemented with ocean water inflow. Differences in the salinity in both types of the seas are conspicuous.

Inland waters carried to the sea also determine the balance of mass and energy. They supply some calories which lead to changes in the sea thermal system and shaping of its thermal relations, which differ from those occurring in the open seas. They also play an important part in chemical and biological processes, by supplying great amount of dissolved and suspended matter. Thus inland seas are characterized by prevalence of terrigenic sediments which arise as a result of sedimentation and precipitation of dissolved material which is carried by river waters. The growing pollution of rivers causes the increase in the load of the rubble carried to the sea, which mostly stays in the sea depths.

\section{GENERAL CHARACTERISTICS OF THE SEMI-ENCLOSED SEAS OF EUROPE AND THE WORLD}

Diversified coasts of the continent of Europe encourage the occurrence of the semi-enclosed seas. First comes the Mediterranean Sea as a semi-enclosed sea with negative balance. Its sub-regions include other semi-enclosed seas, such as the Adriatic Sea, with negative balance, and the Black Sea, having positive balvnce. In the north of Europe there lie typical semi-enclosed seas with positive balance i.e. the Baltic Sea, as well as the White Sea. The Baltic Sea is undoubtedly among the best investigated in respect of hydrology; recently also the Mediterranean Sea has been under organized international investigation. The above-mentioned seas belong to the Atlantic Ocean basin; the White Sea, being a sub-region of the Barents. Sea, is situated in the Arctic Sea basin, which is a mediterranean polar basin of the Atlantic Ocean (Lomniewski et al., 1979).

In the basin of the Atlantic Ocean in the American continent the following semi-enclosed seas can be distinguished: the Gulf of Mexico (negative balance), Gulf of St. Lawrence and Hudson Bay which is also connected with the Arctic Ocean (both seas have a positive balance). In the basin of the Pacific Ocean in the American continent there lies Golfo de California (with negative balance). In the same basin in the Asian continent three semi-enclosed seas with positive balance can be distinguished: the Yellow Sea, separated from the Pacific by the East 
China Sea. the Sea of Japan, with several straits connecting it with the Pacific. and the Sea of Okhotsk, separated from the Pacific by the chain of the Kurile islands. Finally, in the basin of the Indian Ocean there lie two typical semi-enclosed seas with negative balance. i.e. the Red Sea, separated from the ocean by the Gulf of Aden and the Persian Gulf, separated from the ocean by the Gulf of Oman. Comparison of the above-mentioned semi-enclosed seas of the world is given in Table 1. An interesting comparison of the semi-enclosed seas in various climatic conditions has been made by Seibold (1970).

Table 1. Semi-enclosed seas of the world and their chief characteristics (after Z. Mikulski, 1981)

\begin{tabular}{|c|c|c|c|c|c|c|c|}
\hline \multirow{2}{*}{$\begin{array}{l}\text { Conti- } \\
\text { nent }\end{array}$} & \multirow[t]{2}{*}{ Name of sea } & \multicolumn{3}{|c|}{ Morphometric features } & \multirow{2}{*}{\multicolumn{2}{|c|}{$\begin{array}{l}\text { Connection } \\
\text { with ocean } \\
\text { (sea) }\end{array}$}} & \multirow{2}{*}{$\begin{array}{l}\text { Water } \\
\text { ba- } \\
\text { lance }\end{array}$} \\
\hline & & $\begin{array}{r}\text { area } \\
\left(\mathbf{k m}^{2}\right)\end{array}$ & $\begin{array}{r}\text { volume } \\
\left(\mathbf{k m}^{\prime}\right)\end{array}$ & $\begin{array}{c}\text { mean } \\
\text { depth } \\
\text { (m) }\end{array}$ & & & \\
\hline \multirow{3}{*}{ 罗 } & \multicolumn{4}{|c|}{ A. Pacific Occan } & & & \\
\hline & \multirow{3}{*}{$\begin{array}{l}\text { Yellow Sea } \\
\text { Sea of Japan } \\
\text { Sea of Okhotsk } \\
\text { Gulf of California }\end{array}$} & \multirow{3}{*}{$\begin{array}{r}417.000 \\
1.007 .700 \\
1.527 .600 \\
162.200\end{array}$} & \multirow{3}{*}{$\begin{array}{r}17.00 \\
1.360 .400 \\
1.280 .100 \\
131.900\end{array}$} & \multirow{3}{*}{$\begin{array}{r}40 \\
1350 \\
838 \\
813\end{array}$} & \multicolumn{2}{|c|}{$\begin{array}{l}\text { East China Sea } \\
\text { Pacific Ocean }\end{array}$} & $\begin{array}{l}+ \\
+\end{array}$ \\
\hline & & & & & " & $"$ & + \\
\hline & & & & & " & $"$ & - \\
\hline \multirow{4}{*}{ 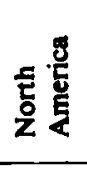 } & \multicolumn{4}{|c|}{ B. Atlanticocean } & & & \\
\hline & \multirow{7}{*}{$\begin{array}{l}\text { Gulf of Mexico } \\
\text { Gulf of Saint Lawrence } \\
\text { Hudson Bay } \\
\text { White Sea } \\
\text { Baltic Sea } \\
\text { Mediterranean Sea } \\
\text { - Adriatic Sea } \\
\text { - Black Sea }\end{array}$} & 1.600 .000 & 2.332 .000 & 1500 & \multicolumn{2}{|c|}{ Atlantic Ocean } & - \\
\hline & & 237.800 & 30.200 & 127 & ," & ," & + \\
\hline & & 1.232 .300 & 157.700 & 128 & & . & + \\
\hline \multirow{4}{*}{ 总 } & & 90.000 & 8.000 & 89 & \multirow{3}{*}{\multicolumn{2}{|c|}{$\begin{array}{l}\text { Barents Sea } \\
\text { North Sea } \\
\text { Atlantic Ocean } \\
\text { Mediterranean Sea }\end{array}$}} & + \\
\hline & & 415.300 & 21.700 & 52 & & & + \\
\hline & & 2.501 .500 & 3.842 .200 & 1540 & & & - \\
\hline & & 420.300 & $\$ 47.000$ & 1300 & , & " & + \\
\hline & \multicolumn{4}{|c|}{ C. Indian ocean } & & & \\
\hline Africa & Red Sea & 437.900 & 215.600 & 491 & \multicolumn{2}{|c|}{ Indian Ocean } & - \\
\hline Asia & Persian Gulf & 238.800 & 6.000 & 25 & ., & ", & - \\
\hline
\end{tabular}

\section{METHODICAL BASIS FOR WATER BALANCE OF THE SEMI-ENCLOSED SEAS}

The shaping of the marine environment by a different relationship of the two factors: land and oceanic is referred to as water balance of the semi-enclosed seas, which indicates the role of the particular elements of the balance in the process of water exchange in the sea. Water balance of the semi-enclosed seas is determined by surface and underground water inflow from the basin $(L)$, precipitation over the sea surface $(P)$ evaporation of water inflow $(M)$; excess $(H)$ of water, if any, is carried back to the ocean, while the increase or loss of water constitutes the storage difference $(\Delta V)$. Precipitation and water evaporation are usually referred to as "vertical water exchange", while the inflow of water from the basin and exchange with the ocean is called "horizontal water exchange". 
A full equation of water balance is as follows (Mikulski 1974):

$$
\begin{aligned}
& (P-E)+(L+M-H)=\Delta V \\
& \text { vertical horizontal storage } \\
& \text { exchange exchange difference }
\end{aligned}
$$

The equation can also be written as follows:

$$
\begin{aligned}
& (P-E+L)-(H-M)=\Delta V \\
& \text { supply of exchange storage } \\
& \text { fresh water with ocean difference }
\end{aligned}
$$

From the hydrological point of view and due to difficulties in determination of exchange with the ocean, we often confine ourselves 'to calculation of balance of fresh waters, which. having considered storage difference, is compared with the so-called "net exchange" with the ocean $(H-M)$; in that case the equation of water balance is more convenient to write as follows:

$$
(P-E+L) \pm \Delta V=(H-M)
$$

The above equation can be represented in cubic kilometres or in height of water layer in the sea $(\mathrm{cm})$; in the latter case, storage difference $(V)$ is determined by the difference in the sea level $(B)$.

\section{ELEMENTS OF WATER BALANCE OF THE SEMI-ENCLOSED SEA}

\subsection{Characteristics of the basin and division of the sea into regions}

In case of inland seas the determination of boundaries and size of the basin is substantial. With reference to the semi-enclosed seas, it is also important to determine the sea boundary in the place of its connection with the ocean (open sea). We are usually guided here by geomorphological conditions (chain of islands closing the sea, occurrence of shallows separating the sea from the ocean, existence of straits, etc.). It is often a conventional boundary; nevertheless, it should be determined and accepted with no reservation. Some inland seas are marked by a considerably developed coastal line and occurrence of separate regions having varied geomorphological and hydrological conditions. So far there have been no univocal criteria of division of seas into regions. In every case criteria are applied which correspond to concrete natural environment.

It is usually geomorphology that is at stake; yet the existent hydrological conditions which determine a certain separateness of the sea region are taken into consideration.

The distinguishing of the regions permits a deep and thorough analysis of the sea and finding out regional peculiarities. There is a need to determine separately boundaries and sizes of basins of those regions (basins of the second order). Thus, the sea basin is divided into regional basins and we arrive at a sort of hydrological regionalization of the basin. 
A classical example is the Baltic Sea (Mikulski 1986). The distinguishing of the basins of the particular regions permits to treat them separately and enrich the knowledge of the rise of hydrological relations and water balance of those regions. A good knowledge of physico-geographical relations of the basin is essential for the later assessment of water and solid matter inflow to the sea.

\subsection{The inflow of water and solid matter from the basin}

The river inflow is usually the main source (in humid climate) of water supply to the sea; particulary in the case of the inland sea with a large surface of the basin. The evaluation of the river inflow is not fraught with major difficulties when there is a sufficient measuring and surveying system in the basin and chiefly control of the river flow of its mouth. The point of departure for such an evaluation is the sub-division of the basin into hydrological regions characterized by similar relations of the river flow, that is the regions in which unit flow is similar within the region. Thus determined regions can be represented by one or more rivers hydrometrically controlled. In other words, we select rivers that are representative of a given region and ascribe a part of the basin to them (a basin of which the rivers flowing into the sea are marked by similar values of the river flow). It is advisable that the boundaries of the regions overlap with the boundaries of part of the basin (the so-called sub-basin) of the previously defined regions of the sea, which facilitates calculation of the river inflow to the particular parts of the sea. Such a method is specially advised in case of the occurrence of a large number of small rivers, of which a full consideration entails the need to carry out painstaking and meticulous calculations of inflow. Due to simplification of calculations it is possible to apply a far-reaching mechanization of calculations and make a detailed analysis of the role of the fluvial inflow in a total water balance.

The knowledge of the value of fluvial inflow also facilitates the estimation of inflow of solid matter that is carried by the rivers to the sea. River measurements of various forms of river rubbles-dragged, floating and dissolved - particularly at the river mouths, allow to estimate a full load of the rubble carried to the sea.

Sub-surface inflow into the sea is a separate and little known problem. However, attempts at estimating this inflow made here and there show its significant share in the total mass of water supplied by rivers. Certainly, development of hydro-geological methods of investigation and advancement of estimation methods may give more reliable results. It should be remembered that hydro-geological conditions, that are different in various part of the world, are of big importance in the sub-surface inflow. Therefore, undue generalization of the problem may in a specific case lead to big errors in estimating this component of the water balance. 


\subsection{The vertical water exchange (precipitation versus evaporation)}

Two factors are involved in the vertical water exchange, namely: precipitation over the sea and evaporation from the sea surface. Both of these factors usually play a minor part in the water balance as their impact is contrary and mutually neutralized. Usually growth of precipitation (in the ingoing part of the equation) is accompanied by growth of evaporation (in the outgoing part). Only in the case of the seas situated in the intertropical climatic zone, the vertical exchange can exceed the horizontal exchange.

Precipitation over the sea is a component difficult to be measured directly; measuring it is still hindered by the lack of observation posts in the open sea. Trial measurements on ships do not give satisfactory results; besides, there do not always exist possibilities of measurements on islands or on parts of the land protruding into the sea. Most often the data obtained from on-shore posts are used; their extrapolation, however, demands knowledge of spatial distribution of precipitation over the sea - which is different from the distribution over the land.

Another equally difficult problem when estimating this component is to define the actual value of precipitation in place of the measured one. There still does not exist a univocal attitude to the question of the value of corrections, not only with reference to the sea conditions but also to the land conditions despite the fact that measuring experiments have been conducted on land for many years. Radar measurements, which permit to define the range of precipitation, can be of some help in estimating precipitation over the sea surface.

Evaporation from the sea surface is the least known component. The estimations of its value, given by various authors, differ considerably from each other. As there exists no possibility of measuring evaporation directly, it is necessary to seek empirical methods enabling a rough estimation of this component on the basis of climatological or aerological data. Few existing methods of this kind can only be used for vast ineets of water. The so-called aero-dynamic method is most frequently applied, using all the on-shore, island and ship observations. Recently, attempts have been made to apply the so-called aero-dynamic method for utilization of aerological observations made around the sea.

\subsection{The water exchange with the ocean (open sea)}

The exchange of water with the ocean is undoubtedly the most difficult component of water balance of the semi-enclosed sea to estimate. By its nature, the movement takes interchangeably in two opposite directions, especially in case of seas with positive balance, in which the outflow of excess waters to the ocean is interrupted by oceanic water inflow during stroms. The movement is chiefly determined by differences in water levels in the sea and in the ocean, as well as by anemobaric conditions. 
As a result of differences in salinity of these waters the double-sided movement may also take place at the same time. In seas with positive balance oceanic water inflow takes place at the sea bottom, while the outflow from the sea to the ocean - in the surface layer; on the contrary, in seas with negative balance, where at the bottom there is the outflow of more salted sea waters, and oceanic water inflow - with slightly smaller salinity - takes place in the surface layer. The scheme of water exchange is shown in Fig. 1. In case of complicated connections between the semi-enclosed sea and the ocean different directions of water movement can be found in different places (e.g. in straits), and even two-way movement in one and the same strait - at different shores.
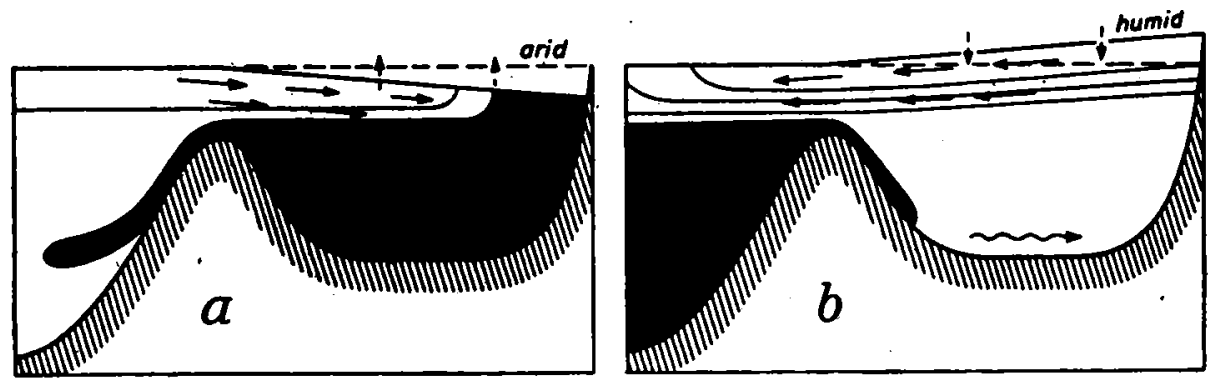

Fig. 1. Schemes of water exchange between semi-enclosed sea and ocean: (a) positive balance sea, (b) negative balance sea: hatchfield saltwater (after G. Brogmus, 1970)

That is why in the water balance of the semi-enclosed sea the movement of water mass is usually analyzed jointly, as the so-called net exchange, in the understanding of the component of the horizontal exchange. The estimation of this component is extremely difficult, and direct measurements are not always possible, not to mention big costs of such measurements. Most often estimates are made by calculating the volume of exchange from the difference of water levels between the sea and the ocean. Dependence of exchange of the existing anemobaric situation (atmospheric pressure as well as strength and direction of wind) is often sought. In case of the Baltic Sea the best effects were obtained from the comparison of results yielded by indirect methods with the results of measurements of water movement in straits. However, new methods and solutions are still sought. When analyzing the volume of water exchange in straits it should be remembered that not always and not the whole mass of oceanic water comes into the semi-enclosed sea and after passing the straits region returns to the ocean. The system of these straits, complicated at times, does not encourage further moveement of oceanic water towards the semi-enclosed sea; on the contrary, the resistance of the water masses of this sea causes that oceanic waters return. 


\subsection{Changes of the water level and the sea capacity: water exchange}

As a result of the formation of water balance there comes an adequate water level, indicating the specified sea capacity, i.e. the quantity of water stored in the sea. Changes of the water level in the accepted balance periods or, more precisely, differences of the water level at the beginning and at the end of the balance period, are in the water balance equation the so-called storage difference being the closure of the water balance equation. Positive value of the difference indicates an increase of the quantity of water in the sea during a balance period, whereas negative value indicates a decrease in the water quantity.

As discussed in the above paragraph 1 changes of the water level are an essential component of the water balance of the sea and their value should be calculated very precisely as each - even very small change of the level - signals a big change of sea retention. Marigraphic records of the chosen representative posts for individual regions of the sea are used as a basis for calculations. Each region can be characterized by different values of the changes with relation to the reasons that cause them. When analysing the marigraphic records, short-duration changes should be disregarded as they are usually caused by local factors and long-duration changes should be taken into account as they are a result of forming of the water balance of the sea.

Calculation of the water balance of the semi-enclosed seas should be based on independene estimation of each balance component separately. Such a procedure permits to estimate the precision of balance calculation. This is also a useful way to correct - from the balance difference - one of the components estimated with least precision.

An important indicator of hydrological regime of the semi-enclosed seas is intensity of entire water exchange in the sea. Entire exchange is defined by means of proportion between the capacity of the sea basin and the value of balance total. The value of the exchange can vary considerably. Exceptionally frequent exchange takes place, for instance, in the Persian Gulf - every two-three years; the Adriatic is also characterized by intensive exchange. The Baltic Sea, in turn, exchanges its water every 42 years, and the Mediterranean Sea every 75 years. Very slow exchange takes place in the Black Sea, namely every 2,600 years. It is certainly a theoretical exchange, since practically the exchange does not comprise the whole mass of water. In case of complex systems of the semi-enclosed seas, a highly differentiated water exchange takes place in each region of such a sea. The Baltic is an interesting example, as its regions constitute a sort of a cascade of sub-systems connected with each other (Mikulski 1987). The scheme of water exchange in the Baltic is shown in Fig. 2.

Studies on the semi-enclosed seas are becoming a more and more urgent problem. Growing exploitation of the seas and their growing pol- 


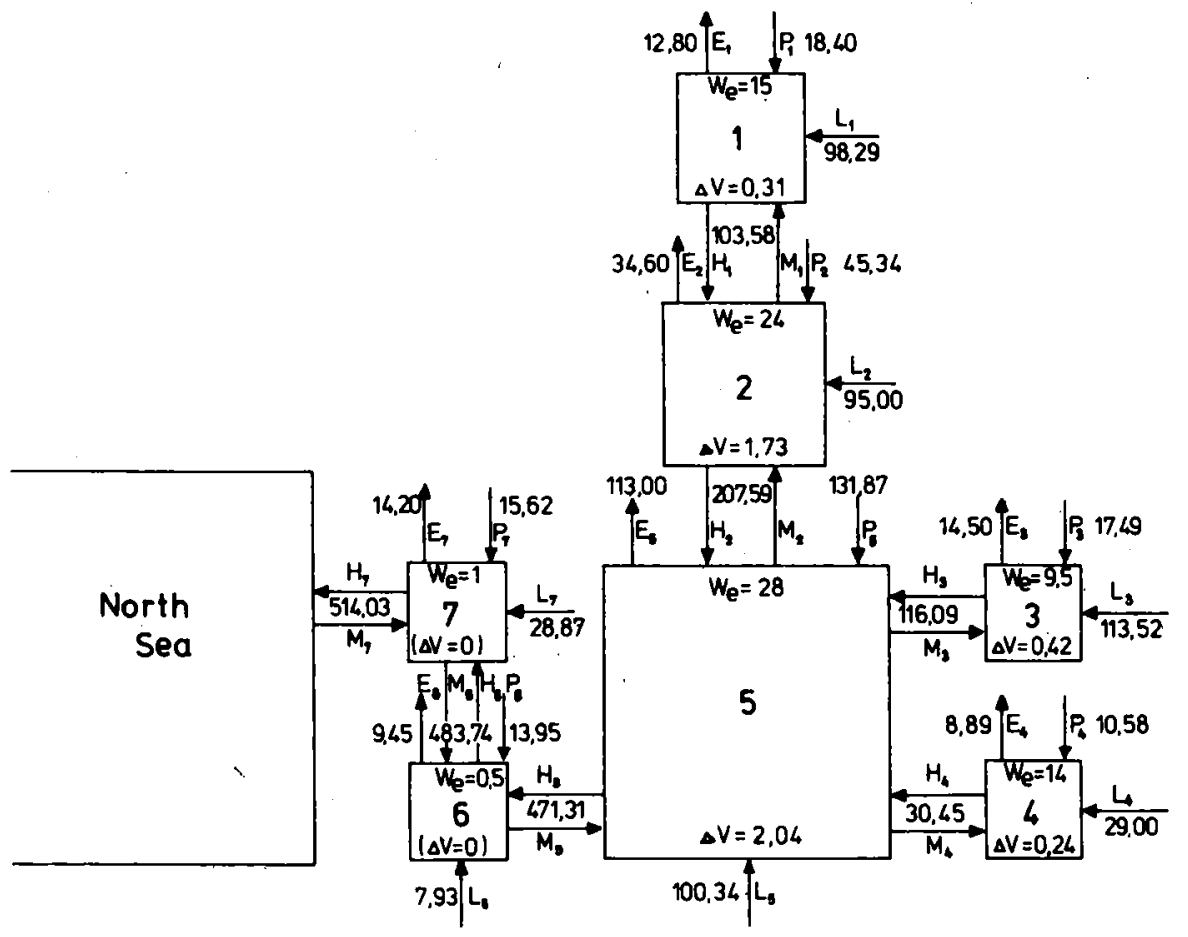

Fig. 2. Scheme of water balance of the Baltic Sea regions in the years $1951-1970\left(\mathrm{~km}^{3}\right)$ (after Z. Mikulski, 1987)

lution require an urgent description of the water balance as a basis for all further scientific and economic ventures since the water balance should be a basis for control and prognosis of the state of sea pollution. It seems that all those circumstances should decisively activate regional hydrological cooperation comprising the drainage areas of the chosen semi-enclosed seas of the world (Falkenmark and Mikulski 1975).

An example of organised studies on semi-enclosed seas is the international UNESCO project "The Water Balance of the Baltic Sea", regarded as an example of regional hydrological cooperation and a model for other semi-enclosed seas of the world. The project was undertaken by all Baltic countries on Poland's initiative as a continuation of studies started within the Hydrologic Conferences of the Baltic Countries in the period between the two World Wars (Falkenmark, Mikulski 1974). This research, carried on since 1971 and aiming at a new approach to historical balance of the sea, has come to an end and the international joint report has been published (Water Balance of the Baltic Sea, 1968). 


\section{REFERENCES}

D ietrich, G., 1970, Ozeanographie. Physische Geographie des Weltmeeres, Braunschweig, $118 \mathrm{p}$

F a lke n m a rk, M., M ikulski, Z., 1974, Hydrology of the Baltic Sea. General background to the International Project, Stockholm - Warszawa, $51 \mathrm{p}$.

Falkenmark, M., Mikulski, Z., 1975, "The Baltic Sea - A semi-enclosed sea, as seen by the bydrologist", Nordic Hydrology, No. 6, pp. 115-136.

Mikulski, Z., 1974, "Water balance of the Baltic Sea (Cooperation of the Baltic countries)", Journal of Hydrological Sciences, No. 1, pp. 89-107.

Mikulski, Z., 1981, "Water balance of the semi-enclosed seas", Geophysica, No. 17, pp. $63-74$.

Mikulski, Z, 1987, "The Baltic Sea as a hydrological system and its water balance", Przeglqd Geofizyczny, XXXII, pp. 21-33 (in Polish).

Seibold, E., 1970, "Nebenmeere im humiden und ariden Klimabereich", Geologische Rundschau, No. 60, pp. 73-105.

"Water Balance of the Baltic Sea", 1986, A Regional Cooperation Project of the Baltic States - International Summary Report. Baltic Sea Environment Proceedings, 16, Helsinki, $176 \mathrm{p}$. 